\title{
Phenol degradation in a three-phase biofilm fluidized sand bed reactor
}

\author{
M. Etzensperger, S. Thoma, S. Petrozzi, I. J. Dunn, Zurich
}

\begin{abstract}
A previous three phase fluidized sand bed reactor design was improved by adding a draft tube to improve fluidization and submerged effluent tubes for sand separation. The changes had little influence on the oxygen transfer coefficients $\left(K_{L} a\right)$, but greatly reduced the aeration rate required for sand suspension. The resulting $12.5 \mathrm{dm}^{3}$ reactor was operated with $1 \mathrm{~h}$ liquid residence time, $10.2 \mathrm{dm}^{3} / \mathrm{min}$ aeration rate, and $1.7-2.3 \mathrm{~kg}$ sand $(0.25-0.35 \mathrm{~mm}$ diameter) for the degradation of phenol as sole carbon source. The $K_{L} a$ of $0.015 \mathrm{~s}^{-1}$ gave more than adequate oxygen transfer to support rates of $180 \mathrm{~g}$ phenol $/ \mathrm{h} \cdot \mathrm{m}^{3}$ and $216 \mathrm{~g}$ oxygen $/ \mathrm{h} \cdot \mathrm{m}^{3}$. The biomass-sand ratios of $20-35 \mathrm{mg}$ volatiles/g gave estimated biomass concentrations of $3-6 \mathrm{~g}$ volatiles $/ \mathrm{dm}^{3}$. Offline kinetic measurements showed weak inhibition kinetics with constants of $K_{S}=0.2 \mathrm{mg}$ phenol $/ \mathrm{dm}^{3}, K_{O 2}=0.5 \mathrm{mg}$ oxygen $/ \mathrm{dm}^{3}$ and $K_{I}=$ $122.5 \mathrm{mg}$ phenol $/ \mathrm{dm}^{3}$. Very small biofilm diffusion effects were observed. Dynamic experiments demonstrated rapid response of dissolved oxygen to phenol changes below the inhibition level. Experimentally simulated continuous stagewise operation required three stages, each with $1 \mathrm{~h}$ residence time, for complete degradation of $300 \mathrm{mg}$ phenol $/ \mathrm{dm}^{3} \cdot \mathrm{h}$.
\end{abstract}

\section{Introduction}

Fluidized sand beds offer a general means of immobilizing mixed cultures for the treatment of water and wastewater. Such reactors have been applied on the laboratory scale as two phase solid-liquid systems for the processes of nitrification, denitrification, and anaerobic degradation $[1,2,3]$. Industrial scale reactors the sand is fluidized by a recirculating flow of liquid, and more recently three phase reactors have been employed using the aeration gas flow as the mechanism for fluidization. Oxygen transfer was found to be influenced only slightly by the biofilm-covered sand, and although the turbulence was vigorous, a stable biofilm was formed when degrading carbohydrates [4].

Degradation of xenobiotics requires specially selected organisms. One means of selection is through continuous operation of a chemostat. Since the specialist organisms almost always grow slowly, care must be taken in maintaining the dilution rate low enough that the organisms are not washed out. Fortuitously, cultures enriched in this way are often found to exhibit wall growth, possibly because the flow rates inadvertently selected for wall growth. Fluidized beds can advantageously be used for selecting organisms for xenobiotic degradation [5]. This technique has seldom been practiced for xenobiotic selection purposes, but has recently been employed under anaerobic conditions [6].

Fluidized beds have been used to immobilize existing xenobiotic strains for reactor developement using two phase [7], and more recently three phase reactors [8, 9]. Phenol degradation has been investigated in two phase [10] and three phase biofilm fluidized bed reactors using activated carbon [8] and coal [10] as a support.

The purpose of the present work was to investigate the suitability of a three-phase reactor for the selection of a mixed culture for the aerobic degradation of phenol, and to study the mass transfer and kinetic aspects of the reactor operation.

\section{Experimental methods}

The reactor, depicted in Fig. 1, was a $12.5 \mathrm{dm}^{3}$ column geometry with removable internal draft tube and conical upper calming section. Air passed through a rotameter, was dispersed through a porous steel sparger at the base, rose through the draft tube, and was separated in the top calming section. The cross-sectional areas of the draft tube and the annular section were both $75 \mathrm{~cm}^{2}$. Overflow liquid passed through a bundle of three tubes, which extended into the reactor outside the draft tube; their diameter was chosen to permit settling of the sand particles. This reactor was the same as that used previously [4], except that the tube bundle replaced the sedimentation tank and the draft tube was added. This design is in principle similar to the reactor of Tang and Fan [8]. A thermostated jacket controlled the reactor temperature. Dissolved oxygen measurement was made with an electrode extending from the top plate into the reactor.

Characterization oxygen transfer capacity of the three phase system was made by measuring $K_{L}$ a dynamically with an oxygen electrode. After gassing-out with nitrogen, the aeration was turned on and a recording was made of the 


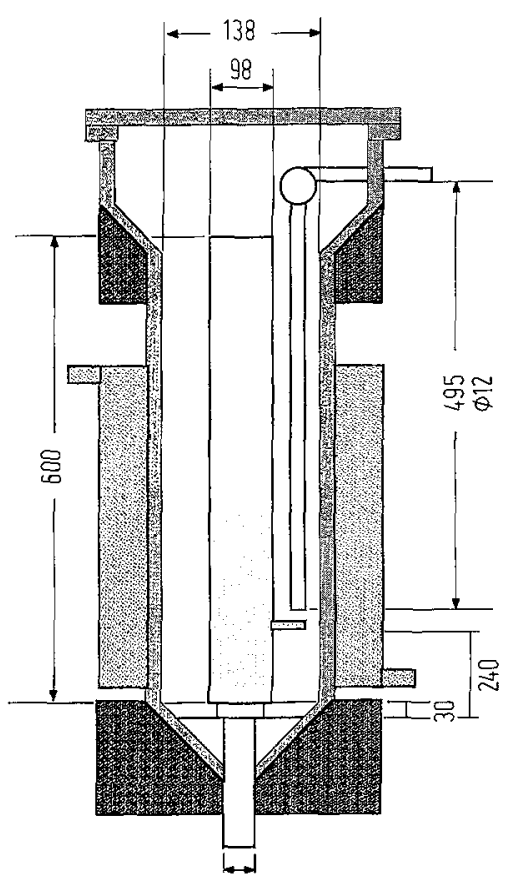

Fig. 1. Schematic drawing of the $12.5 \mathrm{dm}^{3}$ reactor column showing draft tube position

dissolved oxygen concentration. Complete mixing was assumed for the evaluation of $K_{L} a$. Holdup of the gas phase was obtained by measuring the displaced liquid volume. Liquid flow velocities in the annular section were measured by visually timing the passage of small paper markers. Mixing times for phenol were made by injection and rapid sampling.

Off-line analysis was made for oxygen and carbon dioxide in the gas phase (HP gas chromatograph, 5890), Phenol was analyzed by the modified AAP method [11] to $0.1 \mathrm{mg} / \mathrm{dm}^{3}$ accuracy. Biomass was measured by volatile solids. A thermostated, stirred oxygen electrode respirometer was used to measure oxygen uptake rates of sand-biomass samples. Sonic treatment (Labosonic 1510) was used to remove biomass from the sand,

The reactor conditions for biological experiments were as follows: temperature $20^{\circ} \mathrm{C}$, aeration rate normally $10.2 \mathrm{dm}^{3} / \mathrm{min}$, liquid feed rate $12.5 \mathrm{dm}^{3} / \mathrm{h}$ or $1 \mathrm{~h}$ residence time, $\mathrm{pH}$ between 6 and 7 (Tabs. 1, 2).

The sand used was crushed quarz $(0.25-0.3 \mathrm{~mm})$ with a density of $2.22 \mathrm{~g} / \mathrm{cm}^{3}$. The settled bed density was $1.15 \mathrm{~g} / \mathrm{cm}^{3}$ and had a void volume of 0.46 . The reported volumes of sand used can be converted to sand mass by this density factor, thus $2 \mathrm{dm}^{3}$ sand corresponds to $2.3 \mathrm{~kg}$ sand. During the biological experiments the reactor contained between 1.5 and $2 \mathrm{dm}^{3}$ sand. This value varied due to the fact that sand was occassionally carried out.

The feed consisted of concentration solution which was mixed with a tap water stream to obtain the desired phenol concentration. The feed concentrate was a follows: Phenol $1.5 \mathrm{~g} / \mathrm{dm}^{3} \mathrm{~K}_{2} \mathrm{HPO}_{4} 1.5 \mathrm{~g} / \mathrm{dm}^{3}, \mathrm{KH}_{2} \mathrm{PO}_{4} 0.75 \mathrm{~g} / \mathrm{dm}^{3}, \mathrm{MnCl}_{2}$
Table 1. Physical data for $2 \mathrm{dm}^{3}$ sand using aeration rate $10.2 \mathrm{dm}^{3} /$ $\min$

$K_{L} a=0.01 \mathrm{~s}^{-1}$

Gas holdup $=0.08$

Aeration rate for fluidization $=7 \mathrm{dm}^{3} / \min$ or $0.56 \mathrm{vvm}$

Gas velocity required for fluidization (based on draft tube area) $=1.6 \mathrm{~cm} / \mathrm{s}$

Circulation velocity $=25 \mathrm{~cm} / \mathrm{s}$

Mixing time $=12 \mathrm{~s}$

Table 2. Reactor conditions

\begin{tabular}{ll}
\hline Volume: & $12.5 \mathrm{dm}^{3}$ \\
Sand quantity & $1.7-2.3 \mathrm{~kg}$ \\
Sand size: & $0.25-0.35 \mathrm{~mm}$ \\
Residence time: & $1 \mathrm{~h}$ \\
Aeration rate: & $10.2 \mathrm{dm}^{3} / \mathrm{min}$ \\
Temperature: & $20^{\circ} \mathrm{C}$ \\
pH: & uncontrolled; $6-7$ \\
Biomass-sand ratio: & $20-35 \mathrm{mg} / \mathrm{g}$ \\
Biomass concentration: & $3-6 \mathrm{~kg} / \mathrm{m}^{3}$ \\
\hline
\end{tabular}

$0.375 \mathrm{~g} / \mathrm{dm}^{3}, \mathrm{MgSO}_{4} 0.375 \mathrm{~g} / \mathrm{dm}^{3}, \mathrm{MnSO}_{4} 0.375 \mathrm{~g} / \mathrm{dm}^{3}$, $\mathrm{NaCl} 0.375 \mathrm{~g} / \mathrm{dm}^{3},\left(\mathrm{NH}_{4}\right)_{2} \mathrm{SO}_{4} 0.6 \mathrm{~g} / \mathrm{dm}^{3}$, trace element solution $0.5 \mathrm{~cm}^{3} / \mathrm{dm}^{3}$.

The mixed culture starting from activated sludge was adapted to phenol by continuous culture in the fluidized sand bed.

\section{Discussion of results}

\subsection{Physical characterization}

Oxygen transfer coefficients and gas holdups were measured as influenced by aeration rate, sand quantity, and presence of draft tube. In Fig. 2 the data is presented to show the influence of sand quantity on $K_{L} a$ for three aeration rates with the draft tube installed. Apparently the gas rate had a large influence on $K_{L} a$, but the sand had relatively little effect. This situation is confirmed by the gas holdup data of Fig. 3 in which the holdup increased linearly with aeration rate. In Fig. 4 data are given for $K_{L} a$ measured without the draft tube, showing that the draft tube had little influence on $K_{L} a$, although the gas holdup was somewhat decreased by the presence of the draft tube (Fig. 5). This was no doubt due to the fact that the gas was present essential only within the draft tube. Comparison of $K_{L} a$ 's with and without draft tube (Fig. 6) confirms that the draft tube influence was not great; the single data point giving unusually high $K_{L} a$ at the highest sand remains unexplained and was not observed at higher aeration rates (Fig. 2). 


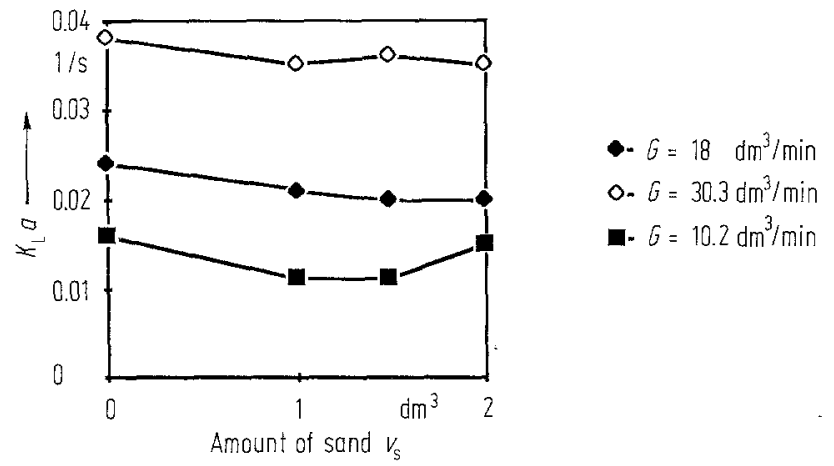

Fig. 2. Dependency of $K_{L} a$ on the amount of sand for three gassing rates with the draft tube

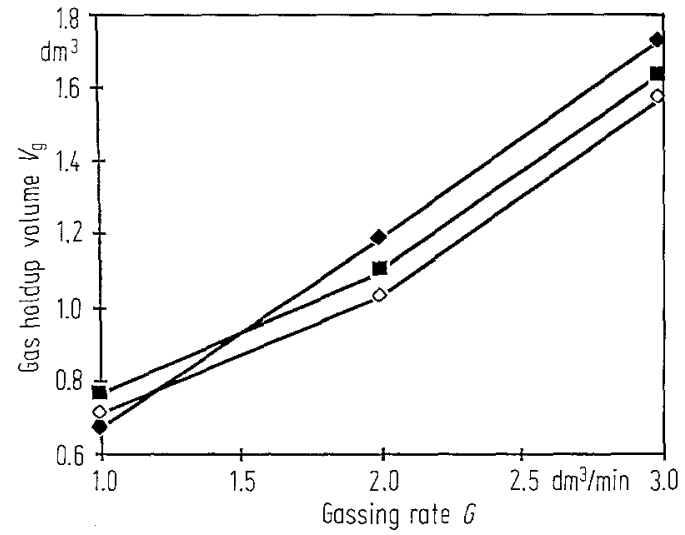

Fig. 3. Dependency of gas holdup volume on the gassing rate for varying amounts of sand with the draft tube

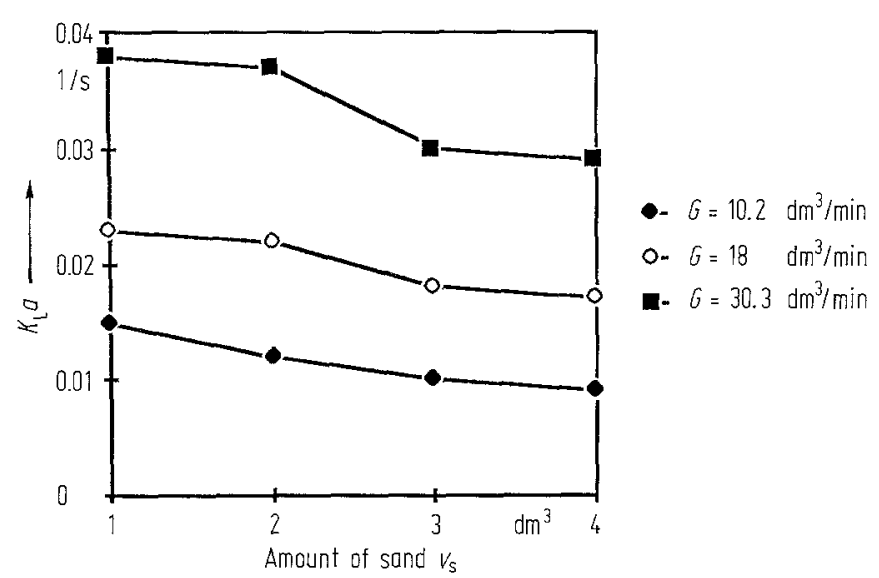

Fig. 4. Dependency of $K_{L} a$ on the amount of sand for three gassing rates without the draft tube

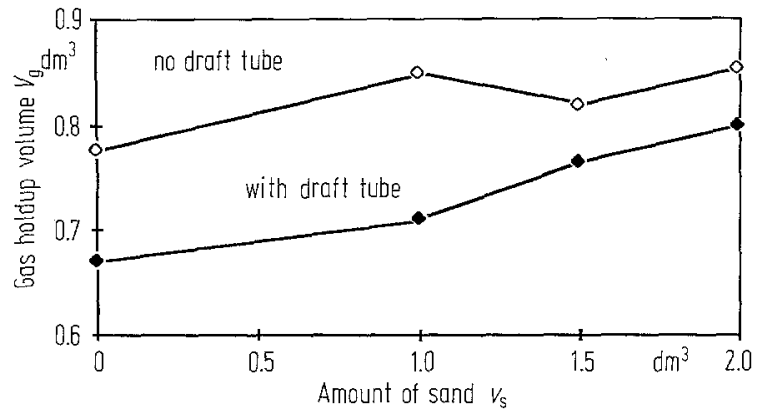

Fig. 5. Comparison of the gas holdups with and without draft tube on the amount of sand for a single gassing rate $\left(10.2 \mathrm{dm}^{3} / \mathrm{min}\right)$

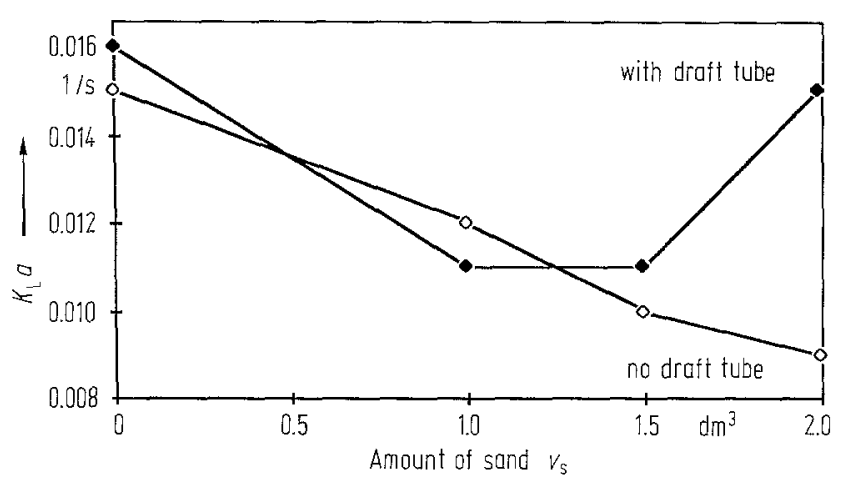

Fig. 6. Comparison of the dependency of $K_{L} a$ with and without draft tube on the amount of sand for a single gassing rate $\left(10.2 \mathrm{dm}^{3} / \mathrm{min}\right)$

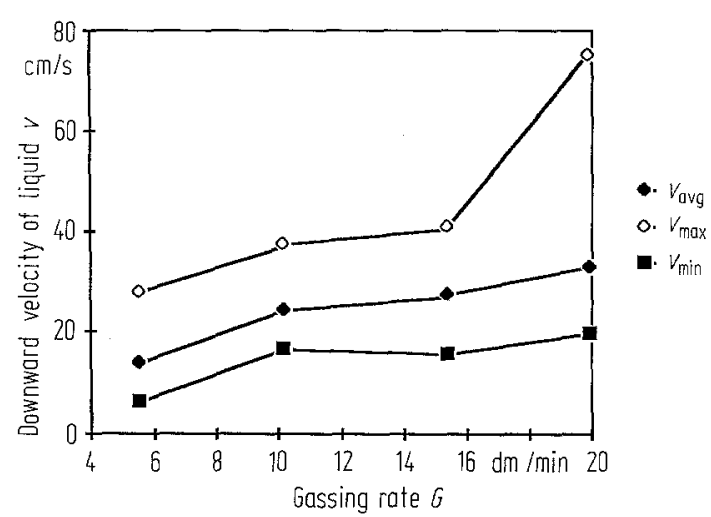

Fig. 7. Downward velocity of liquid in the annular reactor section between wall and draft tube as a function of gassing rate

The measured downward liquid velocities in the annular section between reactor wall and draft tube are given in Fig. 7. The velocities increased roughly linearly with aeration rate. The aeration rates required to completely fluidize various amounts of sand are given in Fig. 8. The draft tube greatly improved the fluidization due to the flow pattern at 


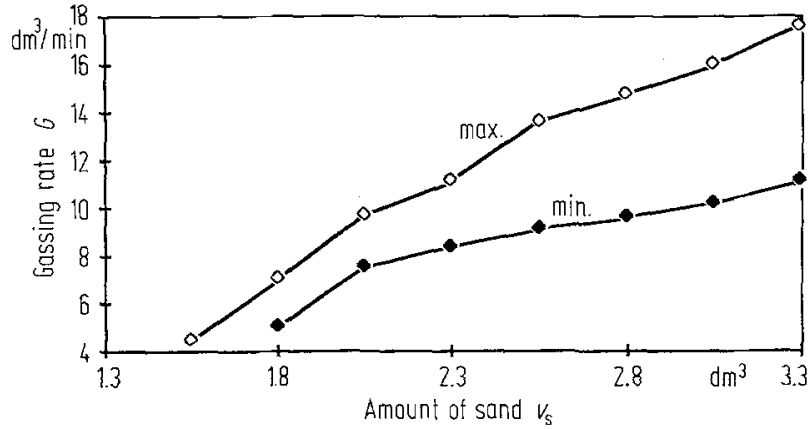

Fig. 8. Gassing rate requirement for complete fluidization as a function of sand quantity

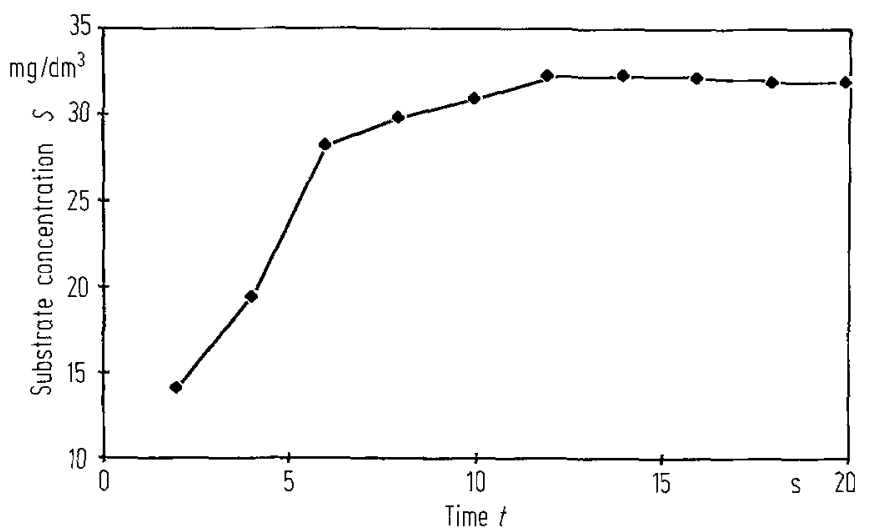

Fig. 9. Mixing time measurement for phenol in the reactor

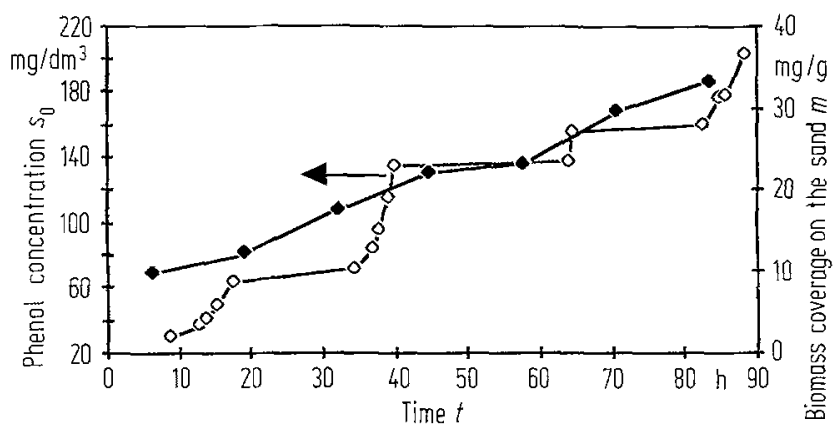

Fig. 10. Change of the biomass coverage on the sand as a function of time as influenced by stepwiese continual increases in the phenol feed concentration

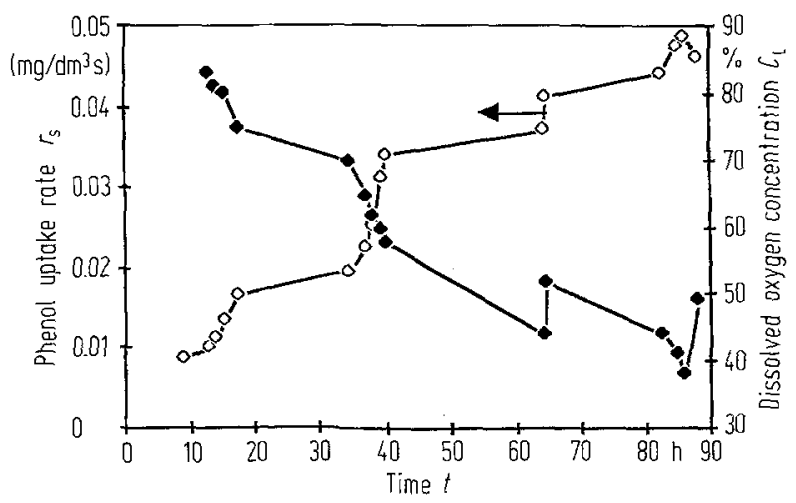

Fig. 11. Change of the phenol uptake rate and the dissolved oxygen concentration as a function of time, same experiment as in Fig. 10

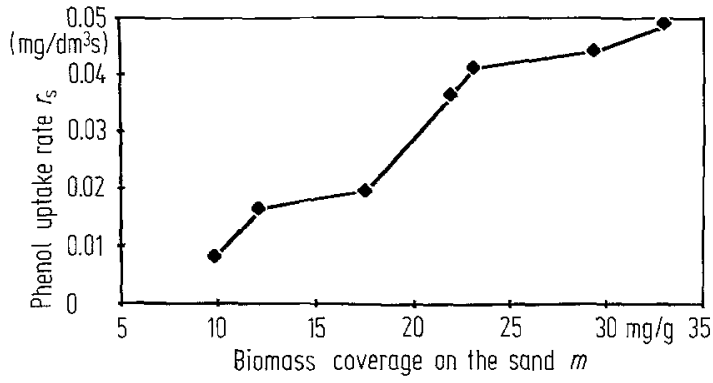

Fig. 12. Influence of the biomass/sand ratio on the phenol uptake rate, same experiment as Fig. 10

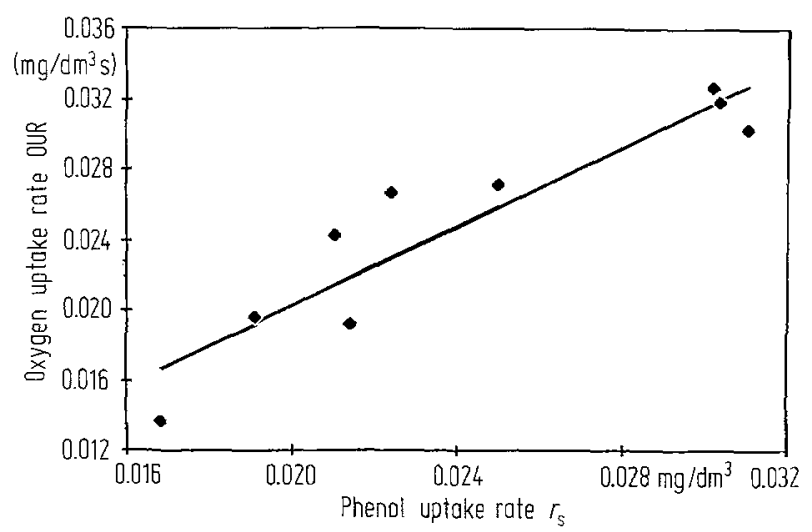

Fig. 13. Variation of oxygen uptake rates with phenol uptake rates, same experiment as Fig. 10

the base of the reactor, as compared with earlier studies [4]. The air-lift circulating flow pattern caused by the draft tube gave a suitably low mixing time for homogenizing a pulse of phenol, as seen in Fig. 9.

\subsection{Biological experiments}

After approximately two weeks an active biofilm culture was obtained for phenol degradation. To test the capacity of the reactor the phenol feed concentration was increased from essentially one steady state to another over a period of $4 \mathrm{~d}$ from a value of $25 \mathrm{mg} / \mathrm{dm}^{3}$ to a value of $200 \mathrm{mg} / \mathrm{dm}^{3}$. Results from this experiment are shown in Figs. 10 to 13. In Fig. 10 the phenol feed concentrations and biomass/sand ratios are given. The phenol concentrations in the reactor, which can be calculated from the rate data in Fig. 11, were below $1 \mathrm{mg} / \mathrm{dm}^{3}$ for feed concentrations below $120 \mathrm{mg} / \mathrm{dm}^{3}$. After hour 40 the concentrations in the reactor were in the range from 10 to $30 \mathrm{mg} / \mathrm{dm}^{3}$, at which range some inhibition can be expected. The dissolved oxygen response in Fig. 11 to the last increase in feed concentration from 180 to $200 \mathrm{mg} / \mathrm{dm}^{3}$ is indicative of inhibition, which caused the rate to decrease. The increase in rates over the first 40 hours is primarily due to an increase in the biomass coverage of the sand particles (biomass/sand ratio). The somewhat slower increase in rates after hour 40 is due to a combined influence of biomass increase and inhibiting values of phenol concentration. Plot- 


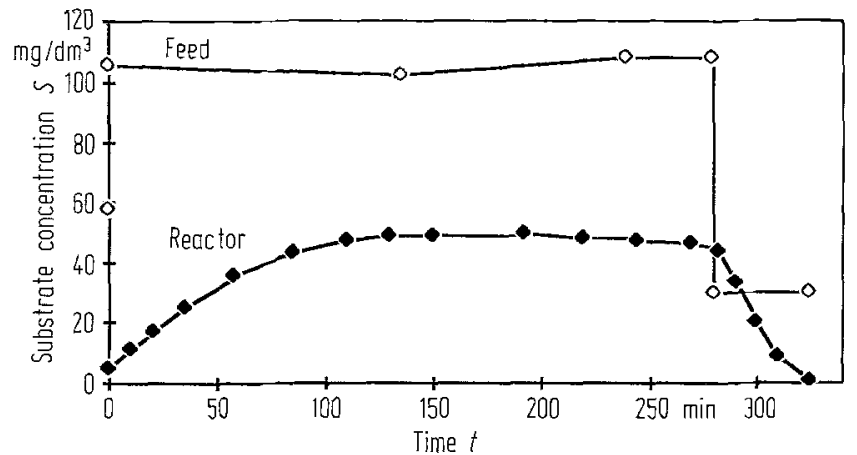

Fig. 14. Response of phenol concentration in reactor to step up and step down changes in the feed concentration

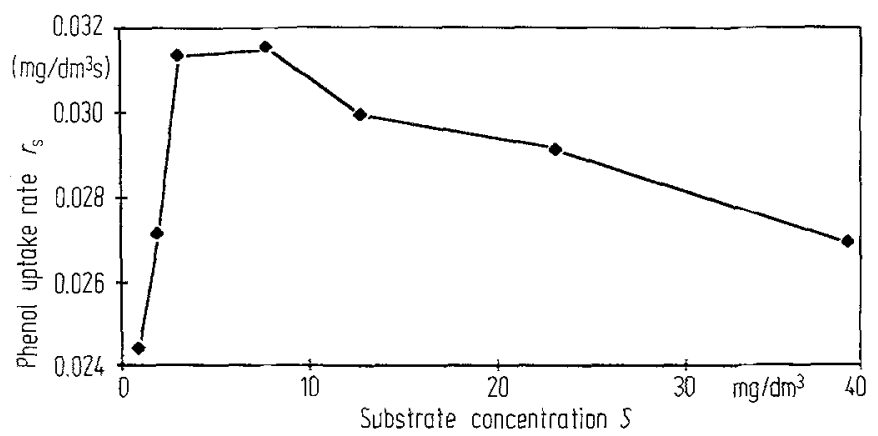

Fig. 15. Phenol uptake rates as a function of phenol concentration in reactor, from steady state experiments

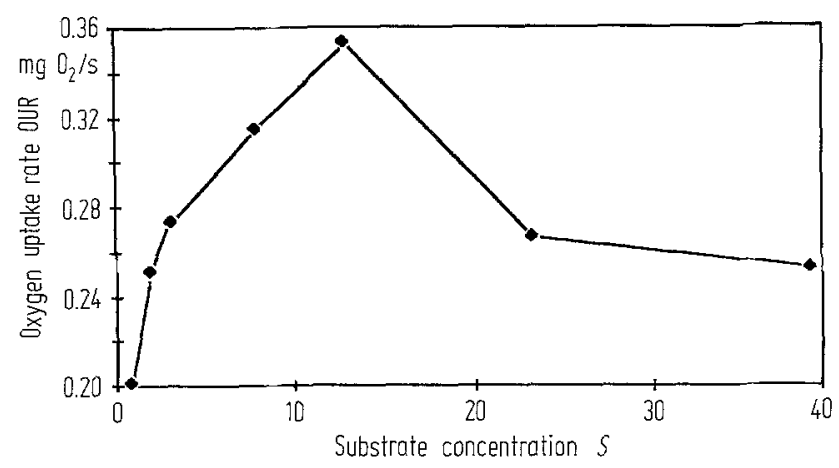

Fig. 16. Oxygen uptake rates as a function of phenol concentration in reactor, from the steady state experiments of Fig. 15

ting the rate data versus the biomass coverage (Fig. 12) indicates that the influence of inhibition was not great. Any phenol gradients in the biofilm would tend to increase the overall rates, thereby masking the inhibition kinetics. The plot of oxygen uptake rates versus phenol uptake rates in Fig. 13 exhibits considerable scatter due to inaccuracies in the gas balancing and give an average value of $1.2 \mathrm{~g} \mathrm{O}_{2} / \mathrm{g}$ phenol. Considering the theoretical oxygen requirement of $2.4 \mathrm{~g} \mathrm{O}_{2} / \mathrm{g}$ phenol, there were probably large amounts of partially oxidized products present. Even lower values had been obtained in earlier work with suspended cultures [12], and a value of 1.4 has been reported for biofilm exper-

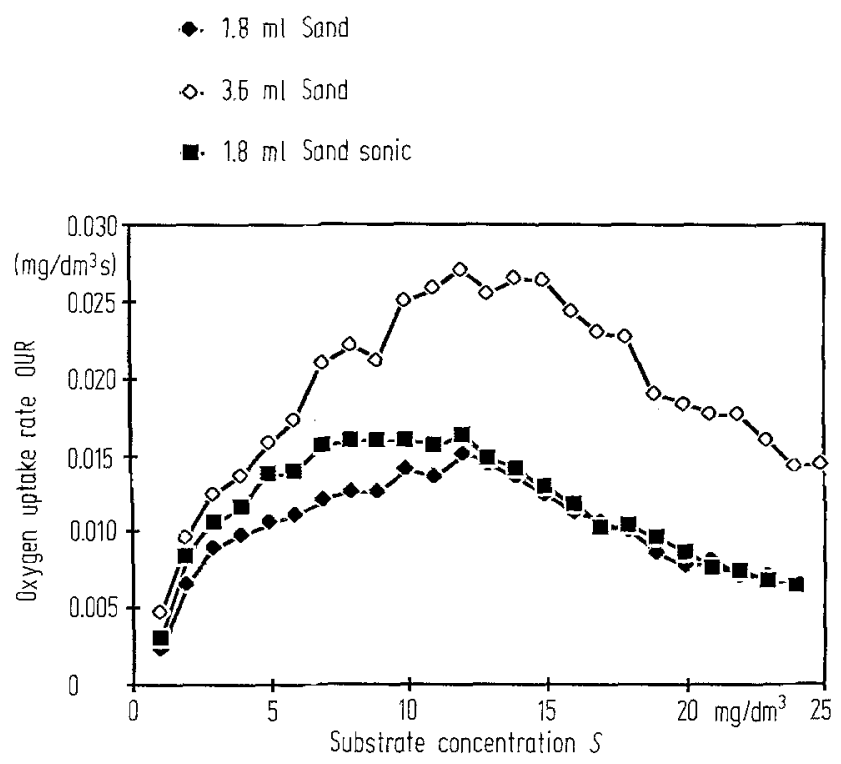

Fig. 17. Oxygen uptake rates as a function of phenol concentration from batch respirometer experiments using biofilm-sand samples with and without ultrasonic treatment

iments [9]. From the maximum rate of $0.05 \mathrm{mg} / \mathrm{dm}^{3} \cdot \mathrm{s}$ $\left(180 \mathrm{~g} / \mathrm{h} \cdot \mathrm{m}^{3}\right)$, assuming $2 \mathrm{~kg}$ of sand in the reactor, gives $1.26 \mathrm{~g}$ phenol $/ \mathrm{h} \cdot \mathrm{kg}$ sand, or in terms of biomass $36 \mathrm{~g}$ phe$\mathrm{nol} / \mathrm{h} \cdot \mathrm{g}$ volatile biomass.

The dynamic response of the reactor to a step up and step down in the feed concentration is given in Fig. 14. Approximately 2 residence times $(1 \mathrm{~h})$ were required to establish a steady state.

Steady state data were used to establish the dependency of rate on phenol concentration (Fig. 15). Corresponding oxygen uptake rates are shown in Fig. 16. The absolute rates were, of course, dependent on the biomass concentrations, which were only approximately constant during these experiments and could not be directly determined.

Biofilm-sand samples were analyzed for the kinetics in a small stirred batch respirometer. Oxygen uptake rates were measured over a range of phenol concentrations and are given in Fig. 17. In these experiments the samples were used both as biofilms and sonically-treated to disperse the organisms, which increased the maximum uptake rates by about $20 \%$. The data from the sonically-treated samples were analyzed for inhibition kinetics using a plot of $1 / O U R$ versus $1 / S$ for the low concentration range to obtain $K_{S}=0.2 \mathrm{mg}$ phenol $/ \mathrm{dm}^{3}$ and $1 / O U R$ versus $S$ for the high range to obtain $K_{I}=122.5 \mathrm{mg}$ phenol $/ \mathrm{dm}^{3}$. The kinetics dependend on the exact nature of the mixed culture, and in earlier work with suspended cultures a value of $K_{I}=40 \mathrm{mg} / \mathrm{dm}^{3}$ had been measured [10].

The $K_{S}$ for oxygen was measured to be about $6 \%$ of saturation, or $0.5 \mathrm{mg}$ oxygen $/ \mathrm{dm}^{3}$. Continuous experiments with feed concentrations of $100 \mathrm{mg}$ phenol $/ \mathrm{dm}^{3}$ using airnitrogen mixtures $\left(65 \% \mathrm{~N}_{2}\right)$ gave a rate of $70.2 \mathrm{mg}$ phenol/ $\mathrm{dm}^{3} \cdot \mathrm{h}$ with $S=29.6 \mathrm{mg} / \mathrm{dm}^{3}$ and dissolved oxygen of $10 \%$ 


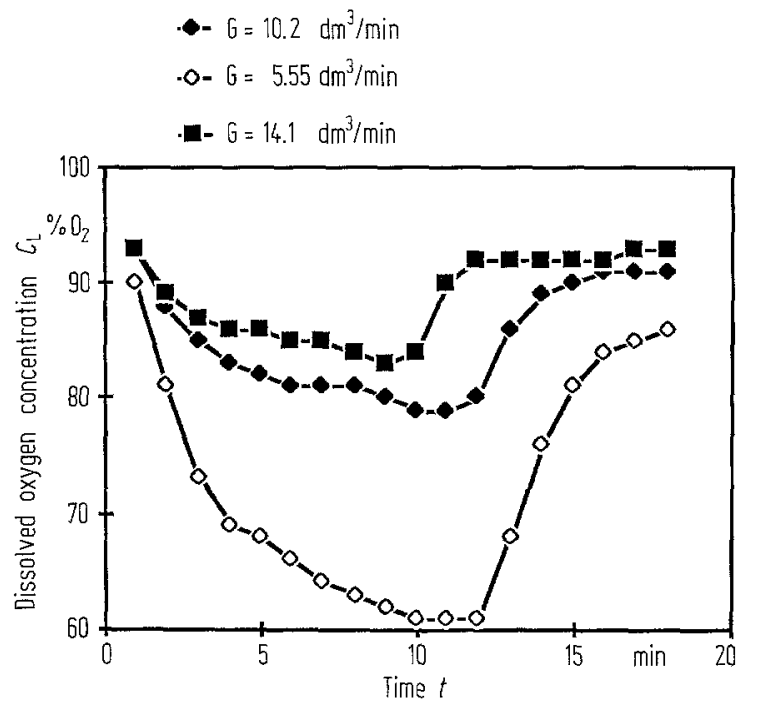

Fig. 18. Profiles of dissolved oxygen versus time from batch phenol degradation experiments at three aeration rates

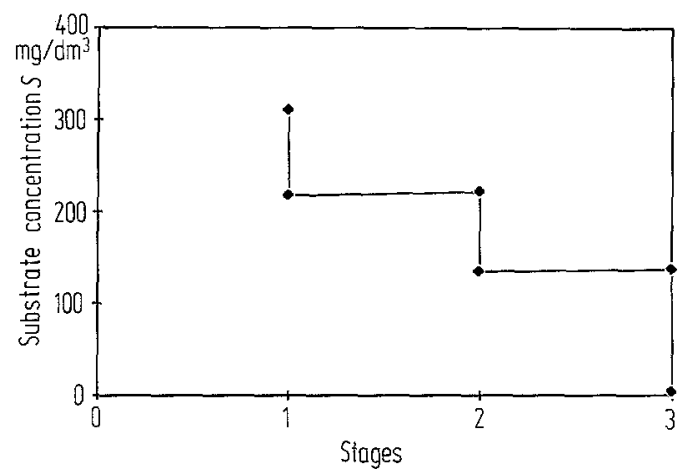

Fig. 19. Simulation of a three stage reaction system by changing feed concentrations

saturation. Under the same conditions with air, a rate of $99.4 \mathrm{mg}$ phenol $/ \mathrm{dm}^{3} \cdot \mathrm{h}$ was observed with $S=0.8 \mathrm{mg} / \mathrm{dm}^{3}$ and dissolved oxygen of $58 \%$ saturation. This data indicated appreciable oxygen limitation at low dissolved oxygen levels, substantiating the $K_{S}$ for oxygen. Operation near the minimum aeration rate necessary for sand suspension, $5.6 \mathrm{dm}^{3} / \mathrm{min}$, was compared with the normal rate, $10.2 \mathrm{dm}^{3} /$ min, and a higher rate, $14.1 \mathrm{dm}^{3} / \mathrm{min}$, in dynamic batch experiments. The results in Fig. 18 clearly indicate that the phenol oxidation rate was highest at the lowest concentrations. When the phenol was exhausted the dissolved oxygen increased.

Figure 17 shows that, in spite of partially inhibition, the rates at higher phenol concentrations remained high and that complete inhibition did not occur. This kinetic form suggests that the use of a stagewise reactor configuration for phenol waste treatment. This was simulated by operating the reactor first at a high feed concentration $\left(310 \mathrm{mg} / \mathrm{dm}^{3}\right)$, measuring the effluent and adjusting the next feed to this level. These experiments gave steady state data for reactor operation at three concentration levels, which were sufficient to

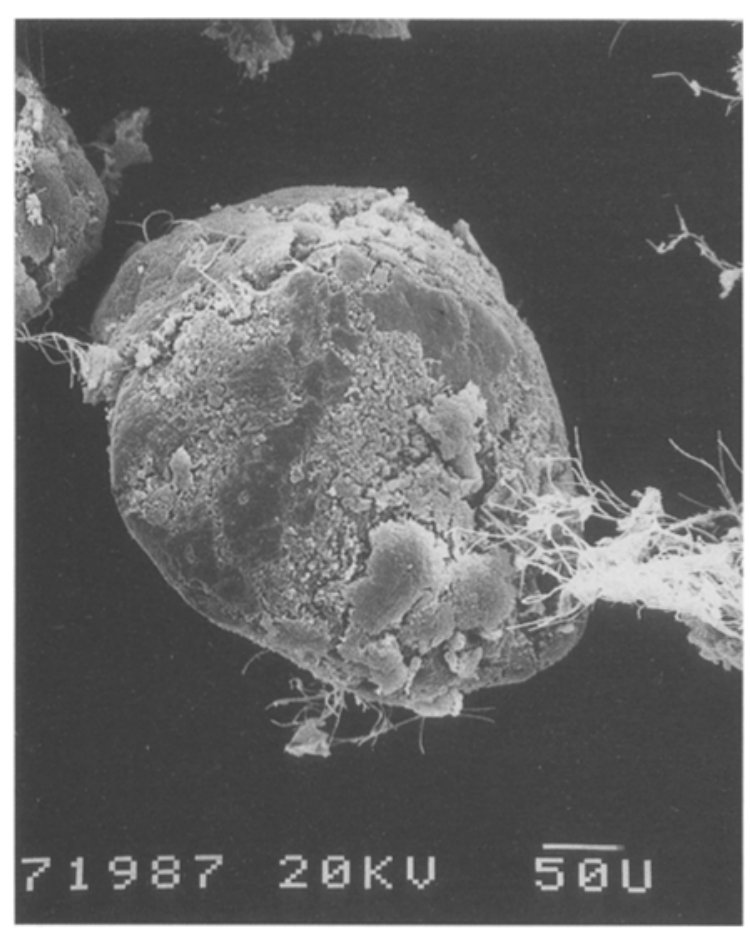

Fig. 20. A biofilm-covered sand particle (electron microscope photo)

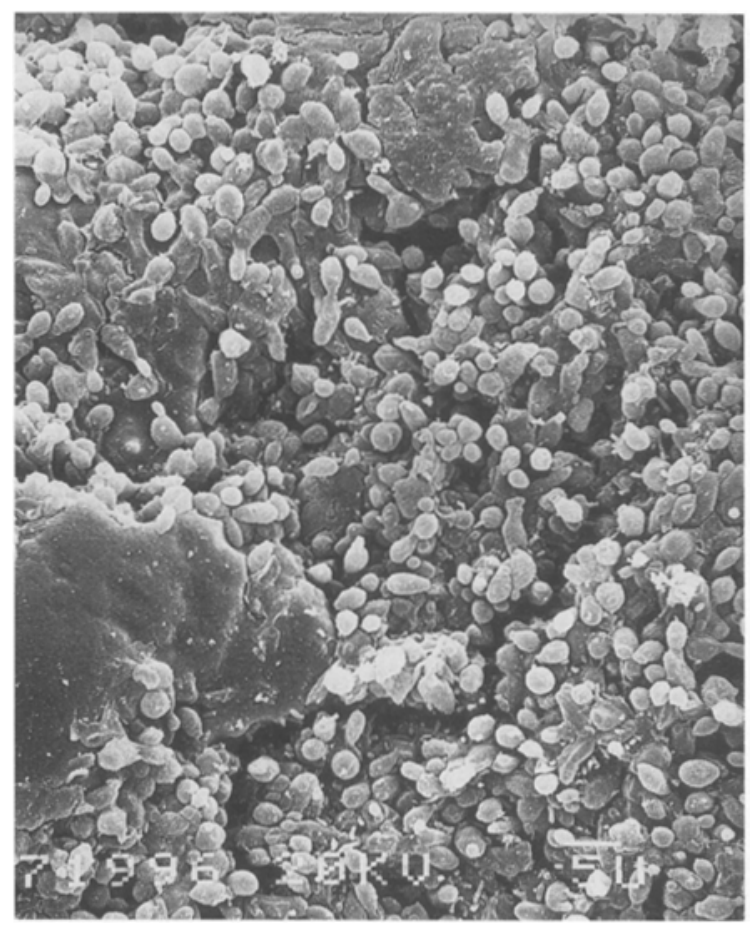

Fig. 21. Close-up of the biofilm which consisted primarily of yeasts

reduce the effluent concentration below $1 \mathrm{mg} / \mathrm{dm}^{3}$. The results are seen in Fig. 19; the rates were approximately $100 \mathrm{mg} / \mathrm{dm}^{3} \cdot \mathrm{h}$ in the first stage, $90 \mathrm{mg} / \mathrm{dm}^{3} \cdot \mathrm{h}$ in the second stage, and $130 \mathrm{mg} / \mathrm{dm}^{3} \cdot \mathrm{h}$ in the third stage.

The biofilm was mechanically stable under the conditions of high turbulence; an electron microscopic photo (Fig. 20) 
shows a sand particle from the first month of operation to be densely covered with biofilm. Higher magnification revealed mainly bacteria. The culture changed over a period of three months and after a second startup, using sand from the first month of operation, the culture comprised mainly yeasts, as seen in Fig. 21.

\section{Concluding discussion}

The effect of the draft tube was mainly one of reducing the aeration rate required for fluidization, with no large change in the measured oxygen transfer rates. If higher oxygen uptake rates are required, the reactor could be operated at higher aeration rates to give correspondingly higher mass transfer coefficients. The draft tube would not be so important at higher aeration rates. However, no disadvantage of the draft tube was noted. For the degradation rates observed in this work the aeration rate for fluidization was above that required to prevent oxygen limitation. For three phase reactors it is useful to match the oxygen transfer to the oxygen uptake and thereby operating at low oxygen concentrations. This could be achieved in the following ways:

- by using lighter carrier particles, allowing a decrease in the aeration rate.

- by using a higher height to diameter ratio to reduce the aeration rate for fluidization while at the same time increasing the oxygen utilization from the gas phase.

The performance of the reactor for phenol degradation is summarized in Table 3 , in terms of the maximum rates achieved. These rates are about twice those obtained previously in suspension culture when the total volume of reactor and settler was considered [13] and about the same as those reported for activated carbon support [8]. The biomass in the reactor was present only as a tight biofilm on the sand particles in a ratio of 20 to $35 \mathrm{mg}$ volatile biomass/g sand, giving an estimated biomass concentration of from 3 to $6 \mathrm{~g} / \mathrm{dm}^{3}$. Carry-over of biomass was effectively avoided with submerged settling tubes for the effluent, eliminating the need of a settler and sand recycle, as used previously [4].

Dynamic experiments demonstrated a rapid response of dissolved oxygen to changes in phenol concentration below the inhibition range. This suggests the use of this variable, or oxygen uptake rate, for control purposes as investigated previously [13].

The kinetic measurements indicated only partial inhibition up to $300 \mathrm{mg}$ phenol/ $\mathrm{dm}^{3}$. This was reflected in nearly zero oder behavior in batch experiments. Very little biofilm diffusion influence was noted in respirometer experiments. The measured constants are given in Table 4 . The $K_{S}$ for oxygen was verified in reactor experiments, which showed strong limitation at $10 \%$ saturation.

Stagewise experiments starting with feed of $300 \mathrm{mg}$ phe$\mathrm{nol} / \mathrm{dm}^{3}$ required three stages to reduce the phenol concentration to zero, demonstrating one possible reactor configuration.
Table 3. Maximum rates observed for phenol degradation in the 3-phase reactor

\begin{tabular}{llll}
\hline Basis/Substrate & Volume & Sand mass & Biomass \\
\hline Phenol & $180 \mathrm{~g} / \mathrm{h} \cdot \mathrm{m}^{3}$ & $1.26 \mathrm{~g} / \mathrm{h} \cdot \mathrm{kg}$ & $3.6 \mathrm{mg} / \mathrm{h} \cdot \mathrm{g}$ \\
Oxygen & $216 \mathrm{~g} / \mathrm{h} \cdot \mathrm{m}^{3}$ & $1.51 \mathrm{~g} / \mathrm{h} \cdot \mathrm{kg}$ & $4.3 \mathrm{mg} / \mathrm{h} \cdot \mathrm{g}$ \\
\hline
\end{tabular}

Table 4. Constants for inhibition kinetics

$K_{\mathrm{S}}=0.2 \mathrm{mg}$ phenol $/ \mathrm{dm}^{3}$

$K_{O 2}=6 \%$ oxygen saturation

$K_{I}=122.5 \mathrm{mg}$ phenol $/ \mathrm{dm}^{3}$

\section{References}

1. Tanaka, H.; Dunn, I. J.: Kinetics of biofilm nitrification. Biotechnol. Bioeng. 24 (1982) 669

2. Kurt, M.; Dunn, I. J.; Bourne, J. R.: Denitrification of drinking water in an autotrophic biological fluidized bed reactor with $\mathrm{H}_{2}$. Biotechnol. Bioeng. 29 (1987) 493

3. Denac, M.; Dunn, I. J.: Packed and fluidized bed biofilm reactor performance for anaerobic wastewater treatment. Biotechnol. Bioeng. 32 (1988) 159

4. Ryhiner, G.; Petrozzi, S.; Dunn, I. J.: Operation of a three-phase biofilm fluidized sand bed reactor for aerobic wastewater treatment. Biotechnol. Bioeng. 32 (1988) 493

5. Dunn, I. J.: Methods for selecting and growing microorganisms in biofilm fluidized sand beds. In: Methods in Enzymology, Vol. 135. New York: Acad. Press 1987

6. Lee Long-de Vallière, C.; Petrozzi, S.; Zürrer, D.; Baier, U.; Dunn, I. J.: Methods of anaerobic degradation of toxic compound in chemical and industrial wastewaters. In: Mizrahi, A. (Ed.): Biological Waste Treatment. Liss, A. New York (1989)

7. Gälli, R.; Leisinger, Th.: Specialized bacterial strains for the removal of Dichloromethane from industrial waste. Conserv. Recycling 8 (1985) $91-100$

8. Tang, W.-T.; Fan, L.-S.: Steady state phenol degradation in a draft-tube, gas-liquid-solid fluidized bed reactor. AIChE J. 33 (1987) 239

9. Wagner, K.; Hempel, D. C.: Biodegradation by immobilized bacteria in an air lift loop reactor. Biotechnol. Bioengr. (in press)

10. Worden, R. M.; Donaldson, T. L.: Dynamics of a biological fixed film for phenol degradation in a fluidized bed reactor. Biotechnol. Bioengr. 30 (1987) 398

11. Donaldson, T. L.; Strandberg, K. W.; Hewitt, J. D.; Shields, G. S.: Environ. Prog. 3 (1984) 248

12. Yang, R. D.; Humphrey, A. E.: Dynamic and steady state studies of phenol biodegradation in pure and mixed cultures. Biotechnol. Bioeng. 17 (1975) 1211

13. Yongacoglu, S.; Dunn, I. J.; Bourne, J. R.: Experiments with an adaptive-questing computer control strategy for the biological oxidation of inhibitory substrates. In: Halme, A. (Ed.): Proc: IFAC Workshop on Modelling and Control of Biotechn. Processes, Helsinki. Pergamon (1983) 291

Received May 20, 1988

I. J. Dunn (corresponding author)

M. Etzensperger

S. Petrozzi

S. Thoma

Bioreaction Engineering Research Group

Chemical Engineering Department

ETH

CH-8092 Zurich 